\title{
Depression, Comorbidities, and Prescriptions of Antidepressants in a German Network of GPs and Specialists with Subspecialisation in Anthroposophic Medicine: A LongitudinalObservational Study
}

\author{
Elke Jeschke, ${ }^{1}$ Thomas Ostermann, ${ }^{2}$ Horst C. Vollmar, ${ }^{3,4}$ \\ Manuela Tabali, ${ }^{1}$ and Harald Matthes ${ }^{1}$ \\ ${ }^{1}$ Havelhoehe Research Institute, Kladower Damm 221, 14089 Berlin, Germany \\ ${ }^{2}$ Center for Integrative Medicine, University of Witten/Herdecke, Gerhard-Kienle-Weg 4, 58313 Herdecke, Germany \\ ${ }^{3}$ Department of General Practice, University of Düsseldorf, Moorenstraße 5, 40225 Düsseldorf, Germany \\ ${ }^{4}$ Institute for General Practice and Family Medicine, University of Witten/Herdecke, Alfred-Herrhausen-Straße 50, \\ 58448 Witten, Germany
}

Correspondence should be addressed to Thomas Ostermann, thomas.ostermann@uni-wh.de

Received 12 July 2012; Accepted 8 October 2012

Academic Editor: Jörg Melzer

Copyright (C) 2012 Elke Jeschke et al. This is an open access article distributed under the Creative Commons Attribution License, which permits unrestricted use, distribution, and reproduction in any medium, provided the original work is properly cited.

\begin{abstract}
Background. Depression is a major reason for counselling in primary care. Our study aims at evaluating pharmacological treatment strategies among physicians specialised in anthroposophic medicine (AM). Methods. From 2004 to 2008, twenty-two German primary care AM-physicians participated in this prospective, multicentre observational study. Multiple logistic regression was used to determine factors associated with a prescription of any antidepressant medication. Results. A total of 2444 patients with depression were included (mean age: 49.1 years (SD: 15.4); 77.3\% female). 2645 prescriptions of antidepressants for 833 patients were reported. Phytotherapeutic preparations from Hypericum perforatum were the most frequently prescribed antidepressants over all (44.6\% of all antidepressants), followed by amitriptyline (16.1\%). The likelihood of receiving an antidepressant medication did not depend on comorbidity after controlling for age, gender, physician specialisation, and type of depression (adjusted OR $(\mathrm{AOR})=1.01$; CI: $0.81-1.26)$. Patients who had cancer were significantly less likely to be prescribed an antidepressant medication than those who had no cancer ( $\mathrm{AOR}=0.75$; CI: 0.57-0.97). Conclusion. This study provides a comprehensive analysis of everyday practice for the treatment of depression in AM -physicians. Further analysis regarding the occurrence of critical combinations is of high interest to health services research.
\end{abstract}

\section{Background}

Depression is one of the three leading causes of disease burden worldwide strongly correlated with increased morbidity and a major reason for counselling and primary patient care $[1,2]$. Depending on the study origin and setting, the prevalence of depression in the general population is estimated between $10 \%$ and $25 \%$ in females and $5-12 \%$ in males with a one-year incidence rate of approximately $2 \%$ [3-5]. Thus, early detection and treatment of depression is a major task for health care policy makers. Due to increasing patient numbers and the development of new antidepressive drugs, family physicians today play an important role in the treatment of depressed patients $[6,7]$. Although approximately $40 \%$ of patients with depression still remain untreated, those patients who decide to consult a therapist are more likely to see a family physician than a psychiatric specialist for both diagnosis and treatment. This is quite important as knowledge and accuracy of nonpsychiatric physicians in treating depression have a great influence the outcome of the illness.

Although research has significantly advanced in the last years, and depression is now generally more acknowledged as an important factor in primary care, patients, relatives, 
and physicians still have reservations and prejudices against pharmaco- or psychotherapy, which may aggravate a sufficient and individualized treatment of depression in primary care and may account for insufficient treatment of depressive symptoms [7]. Studies have shown that only a small amount of primary care patients diagnosed with depression receive appropriate care, which may further lead to poor treatment outcome and increased mortality $[4,7]$.

Accordingly, national guidelines about depression treatment in primary care are a key area of public policy. In Germany that is, the development of a German National Disease Management Guideline (DM-CPG) for depression was induced to increase transparency and improve patient care $[6,8,9]$.

With respect to complementary and alternative medicine (CAM), guidelines from Germany, Canada, and Switzerland have listed the phytopharmaceutical preparation of Hypericum perforatum [6, 10, 11] which is traditionally used quite frequently for mild and moderate depressions. Moreover its effectiveness for unipolar depressive episodes was shown in systematic reviews and meta-analyses [12, 13]. But also other drugs from phytotherapy or homoeopathy may have a potential in the treatment of depression $[14,15]$. However, the prescribing of antidepressants is influenced by physician-as well as patient-related factors, and less is known about prescribing habits of physicians in primary care particularly of those being specialized in CAM.

The present study, thus, aims to analyse prescribing patterns in a network of GPs and specialists with subspecialisation in anthroposophic medicine (AM) for patients who experienced a new episode of depression and to investigate conformity and variations in antidepressant prescriptions. It was hypothesized that (a) Hypericum perforatum was the most frequently prescribed antidepressant and (b) that patients with co-morbidities were more likely prescribed any antidepressant medication.

\section{Methods}

Physicians for the EvaMed Network were recruited through the German National Association of Anthroposophic Physicians (GAÄD) in 2004 [16]. At that time, 118,085 primary care physicians were practising in Germany. Of those, 626 $(0.5 \%)$ primary care physicians were members of the GAÄD. For a physician to be eligible to participate in the study, his or her medical practice had to meet a number of technical requirements, including the presence of a special computerized patient documentation system (DocExpert, DocConcept, TurboMed, Duria, PDE-Top, and Medistar), a local area network (LAN) connection, and Microsoft Windows and Internet Explorer (i.e., as client software). From the 626 physicians of the GAÄD, $362(57.8 \%)$ met these criteria based on self-reported information and were contacted. Physicians were required to give their informed consent to participate in the EvaMed Network and to report all detected serious ADRs (definition provided below "data collection and classification of ADRs") to the EvaMed Network. A total of 38 physicians from 12 of the 16 federal German states finally agreed to participate in EvaMed, covering 6.1\% of the overall primary care physicians of the GAÄD [17]. They all had practised for at least five years in primary care in addition to completing training in anthroposophic medicine.

For our study, 16 physicians specialized in paediatrics, dermatology, and gynaecology were excluded from the study which led to 22 physicians who participated in this study.

The present study is based on secondary data provided by the physicians. As such, the recommendations for good practice in secondary data analysis (e.g., anonymization of data on prescriptions and diagnoses) were developed by the German Working Group on the Collection and Use of Secondary Data were applied in full [18].

Patients were included if they had at least one diagnosis of depression according to the 10th revision of the International Classification of Diseases (ICD10: F32 or F33) during a 5year study period $(01 \cdot 01 \cdot 2004-01 \cdot 01 \cdot 2009)$. Patients were excluded if patients were $<18$ years of age. Patients were also excluded if there was no new diagnosis of depression during the study period. "New diagnosis" of depression was operationally defined as having no diagnosis of depression before and no prescription of any antidepressant medication during the 6 months preceding the index diagnosis. Patients who had no office visit before the index depression diagnosis were also excluded because it was not able to distinguish, whether the index diagnosis represented either a new diagnosis of depression or the entry of an established diagnosis of depression for a new patient. Finally, we also excluded patients with a recorded diagnosis of mania (F30), bipolar disorder (F31), or schizophrenia (F20) because it was thought that these patients would be treated differently.

During the study, physicians continued to follow their routine documentation procedures, recording diagnoses, and all prescriptions for each consecutive patient using their existing computerized patient documentation system. These data were exported to the QuaDoSta postgreSQL database hosted in each practice [19]. Physicians used a browser-based interface to match individual diagnoses with the corresponding drugs or remedies that had been prescribed. Prescribed drugs were documented using the German National Drug Code. Diagnoses were coded according to the 10th revision of the International Classification of Diseases (ICD-10).

Depression was classified as "depressive episode" (ICD10: F32) or "recurrent depressive disorder" (ICD10: F33). Comorbidities were classified as coronary heart disease (ICD10: I20-I25), cerebrovascular disease (ICD10: I60-I69), diabetes mellitus (ICD10: E10-E14), cancer (ICD10: C00-C97), congestive heart failure (ICD10: I50), and chronic obstructive pulmonary disease (COPD; ICD10: J44). Multi-morbidity was considered if a patient had at least two co-morbidities.

Study investigators identified all drugs and remedies prescribed for depression. Each substance was classified using the Anatomical Therapeutic Chemical Index German version (ATC). Antidepressant medication was clustered into non-selective monoamine reuptake inhibitors (NSMRIs; ATC: N06AA), selective serotonin reuptake inhibitors (SSRIs; ATC: N06AB), monoamine oxidase inhibitors (MAOIs; ATC: N06AF), non-selective monoamine oxidase A inhibitors (ATCs: N06AG), other antidepressants (e.g., bupropion, 
mirtazapine, and nefazodone; ATC: N06AX), and phytotherapeutic antidepressants (N06APs).

Statistical analysis was performed with SPSS 18.0 for Windows. Descriptive analysis was used to determine prescription rates. Means and standard deviations (SDs) were calculated for continuous data. In cases where data were not normally distributed, medians and interquartile ranges (IQRs) were reported. Subgroup analyses of prescribing rates were performed for patient age (18-39 years, 40-59 years, and 60 years and older), gender, and co-morbidities. The two-tailed chi-square test was used to analyse differences in prescription rates. A $P$ value of less than 0.05 was regarded as indicating a statistically significant difference.

Odds ratios (ORs) and 95\% confidence intervals (CIs) were calculated using multiple logistic regression with any antidepressant being prescribed medication as the outcome variable. For each outcome ORs were calculated for patients who had and did not have each of the co-morbidities as well as for who had and did not have any of the $6 \mathrm{co}-$ morbidities. After calculating unadjusted OR, two models including potential confounders were determined. Model 1 was controlled for patient age and gender, and model 2 was controlled for patient age, gender as well as for physicians' gender and specialisation and type of depression. Patient age was introduced in the model as a continuous variable.

\section{Results}

Of the 22 physicians, 17 were GPs (77\%) and 5 were specialists working as GPs (23\%). The participating physicians did not differ significantly from the overall population of physicians certified in anthroposophy in Germany $(n=362)$ in terms of age (mean $=49.4 ; \mathrm{SD}=6.3$ years versus mean $=47.5 ; \mathrm{SD}=6.1$ years; $P=0.709)$ or gender $(60.0 \%$ versus $62.2 \%$ men; $P=0.917$ ) and were only slightly younger and consisted of a similar percentage of women compared to all office-based physicians in Germany (mean 52.0 years; $61.2 \%$ men) [20].

During the 5-year study period, a total of 2444 patients with depression were included. The inclusion process is shown in Figure $1.73 .4 \%$ of all patients were treated by a GP $(n=1793), 17.9 \%$ by an internist $(n=437)$, and the remaining $8.8 \%$ of the patients were treated by a neurologist $(n=214) .77 .3 \%$ of the patients were female $(n=1889)$. The mean age of the patients was 49.1 years $(\mathrm{SD}=15.4)$. Altogether, $26.8 \%$ of the patients were $18-39$ years $(n=656)$, $49.8 \%$ were $40-59$ years $(n=1218)$, and $23.3 \%$ were 60 years or older $(n=570)$. Depression was classified as depressive episode $(88.3 \%)$ and recurrent depressive disorder (11.7\%). There was no significant difference according to type of depression and age group $(P=0.789)$ or gender $(P=0.658)$.

In total, $8.3 \%$ of all patients $(n=204)$ had two or more co-morbidities and were, therefore, classified as multimorbid. The most frequent co-morbidities were cancer ( $14.4 \%$ of all patients), coronary heart disease $(8.3 \%)$, and diabetes mellitus (7.1\%). Table 1 provides a detailed overview of the co-morbidities of the participating patients according to patient age and gender.

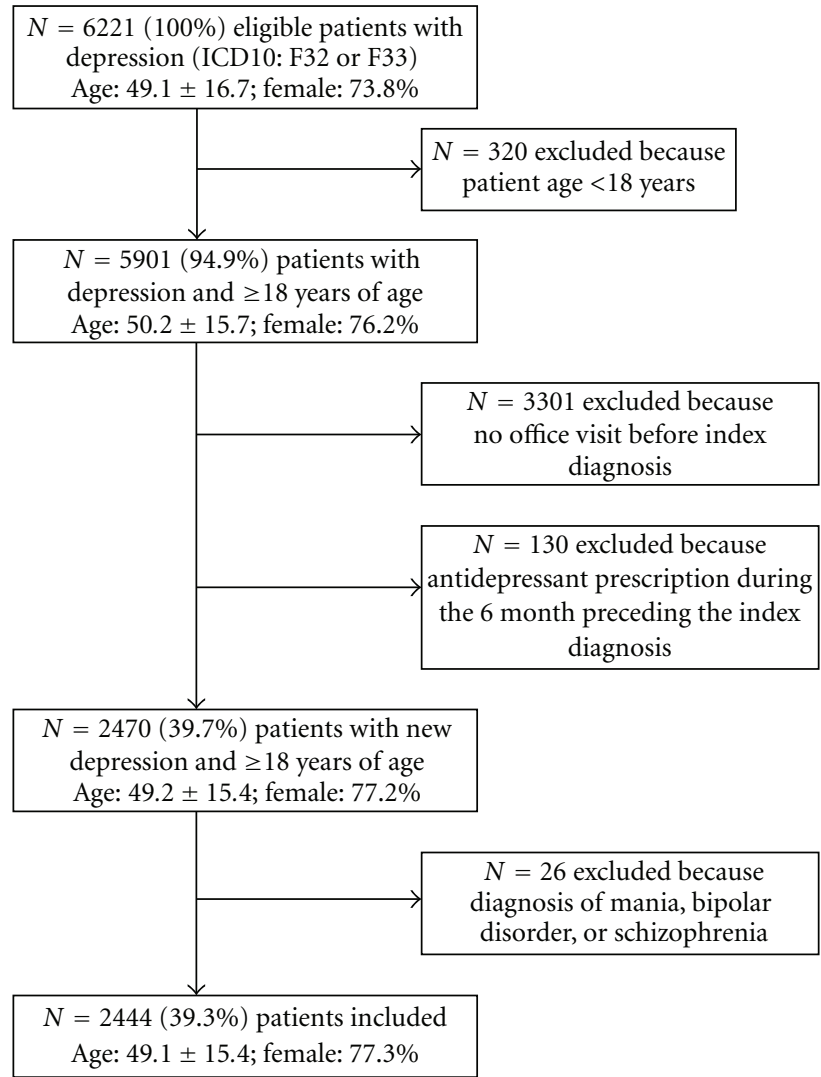

FIgURE 1: Flow chart of the inclusion process.

Overall, 833 patients were prescribed an antidepressant medication, representing $33.9 \%$ of patients who experienced a new episode of depression. In total, 2645 prescriptions of antidepressants for these patients were reported. They were nearly uniformly distributed over the four quarters (1st quarter: 630 (23.8\%), 2nd quarter: 645 (24.4\%), 3rd quarter: $616(23.3 \%)$, and 4 th quarter: $754(28.5 \%))$.

Table 2 gives an overview of the prescribed antidepressants. Phytotherapeutic preparations of Hypericum perforatum were the most frequently prescribed antidepressants over all (44.6\% of all antidepressants). The most common class of conventional antidepressants prescribed was the NSMRI class, and amitriptyline was the most commonly prescribed individual medication.

Table 3 gives a detail overview of the included patients according to antidepressant medication. Phytotherapeutic preparations from Hypericum perforatum were prescribed to 539 of 833 patients with any antidepressant medication (64.7\%), followed by NSMRI (28.2\%), and SSRI (16.8\%). The proportion of patients with antidepressant medication was especially high among neurologists $(76.2 \%)$. The proportion of patients being prescribed any antidepressant medication increased with patient age from $27.7 \%$ of patients under 40 years to $44.4 \%$ of patients of 60 years or older. Patients with multi-morbidity were more likely to receive an antidepressant than patients without co-morbidity $(47.1 \%$ versus $32.9 \% ; P=0.016$ chi-square test). The differences 
TABLE 1: Characteristics of the study population according to co-morbidities, age, and gender.

\begin{tabular}{|c|c|c|c|c|c|c|}
\hline \multirow{3}{*}{ Comorbid condition } & \multirow{3}{*}{$\begin{array}{l}\text { Patients } \\
N(\%)\end{array}$} & \multicolumn{3}{|c|}{ Age group [years] } & \multicolumn{2}{|c|}{ Gender $[\%]$} \\
\hline & & $<40$ & $40-59$ & $\geq 60$ & Male & Female \\
\hline & & $n(\%)$ & $n(\%)$ & $n(\%)$ & $n(\%)$ & $n(\%)$ \\
\hline Coronary heart disease & 202 & $7(3.5)$ & $71(35.1)$ & $124(61.4)$ & $66(32.7)$ & $136(67.3)$ \\
\hline Cerebrovascular disease & 99 & - & $21(21.2)$ & $78(78.8)$ & $26(26.3)$ & $73(73.7)$ \\
\hline Diabetes mellitus & 174 & $9(5.2)$ & $54(31.0)$ & $111(63.8)$ & $66(27.9)$ & $108(62.1)$ \\
\hline Cancer & 351 & $19(5.4)$ & $162(46.2)$ & $170(48.4)$ & $81(23.1)$ & $270(76.9)$ \\
\hline Congestive heart failure & 113 & $1(0.9)$ & $12(10.6)$ & $100(88.5)$ & $23(20.4)$ & $90(79.6)$ \\
\hline Chronic obstructive pulmonary disease & 68 & $8(11.8)$ & $25(36.5)$ & $35(51.5)$ & $19(27.9)$ & $49(72.1)$ \\
\hline \multicolumn{7}{|l|}{ Comorbidities } \\
\hline 0 & 1736 & $614(35.4)$ & $921(53.1)$ & $201(11.6)$ & $358(20.6)$ & $1378(79.4)$ \\
\hline 1 & 504 & $40(7.9)$ & $257(51.0)$ & $207(41.1)$ & $142(28.2)$ & $362(71.8)$ \\
\hline$\geq 2$ & 204 & $2(1.0)$ & $40(19.6)$ & $162(79.4)$ & $55(27.0)$ & $149(73.0)$ \\
\hline Total & 2444 & $656(26.8)$ & $1218(49.8)$ & $570(23.3)$ & $555(22.7)$ & $1889(77.3)$ \\
\hline
\end{tabular}

TABLE 2: Top 10 of prescribed antidepressants.

\begin{tabular}{|c|c|c|c|c|c|c|}
\hline Rank & Substance & ATC & Type & $N$ & $\%$ & Cum \% \\
\hline 1 & Hypericum perforatum & N06AP & Phytoceutical $^{1}$ & 1180 & 44.6 & 44.6 \\
\hline 2 & Amitriptyline & N06AA09 & NSMRI & 426 & 16.1 & 60.7 \\
\hline 3 & Mirtazapine & N06AX11 & NaSSA & 200 & 7.6 & 68.3 \\
\hline 4 & Citalopram & N06AB04 & SSRI & 197 & 7.4 & 75.7 \\
\hline 5 & Doxepin & N06AA12 & NSMRI & 140 & 5.3 & 81.0 \\
\hline 6 & Opipramol & N06AA05 & TCAs $^{2}$ & 104 & 3.9 & 85.0 \\
\hline 7 & Venlafaxine & N06AX16 & SSNRI & 69 & 2.6 & 87.6 \\
\hline 8 & Trimipramine & N06AA06 & NSMRI & 52 & 2.0 & 89.5 \\
\hline 9 & Fluoxetine & N06AB03 & SSRI & 51 & 1.9 & 91.5 \\
\hline 10 & Paroxetine & N06AB05 & SSRI & 46 & 1.7 & 93.2 \\
\hline $11-28$ & Other $<1.7 \%^{3}$ & & & 138 & 9.4 & 100.0 \\
\hline Total & & & & 2645 & 100.0 & 100.0 \\
\hline
\end{tabular}

MAOIs: nonselective, monoamine oxidase A inhibitors; NaSSAs: noradrenergic and specific serotonergic antidepressants; NSMRIs: non-selective monoamine reuptake inhibitors; TCAs: tricyclic antidepressants; SSRIs: selective serotonin reuptake inhibitors; SSNRIs: selective serotonin and noradrenergic reuptake inhibitors.

${ }^{1}$ Two of the primary active constituents of Hypericum perforatum are hyperforin and adhyperforin. Hyperforin and adhyperforin are wide-spectrum inhibitors of the reuptake of serotonin, noradrenaline, glutamate, dopamine, and GABA.

${ }^{2}$ Although opipramol is a member of the tricyclic antidepressants, today it is typically used in the treatment of generalized anxiety disorders (GAD).

${ }^{3}$ Others drugs: for example, Bupropion (NDRIs: noradrenergic and dopaminergic reuptake inhibitors) and nefazodone (DSAs: dual serotonergic antidepressants).

in age and co-morbidities were only due to conventional antidepressants, especially to NSMRI, whereas there was no difference in the prescription rates of phytotherapeutic preparations from Hypericum perforatum.

As shown in Table 4, the likelihood of being prescribed an antidepressant medication was not significantly different for persons who had a co-morbid condition compared with those who did not have a co-morbid medical condition after controlling for age and gender (model 1: adjusted $\mathrm{OR}=0.88$; CI: 0.71-1.09) and after controlling for further potential confounder (model 2: adjusted $\mathrm{OR}=1.01 ; \mathrm{CI}$ : 0.81-1.26). But there were significant differences according to the presence or absence of the individual co-morbidities.
The adjusted OR for receiving any antidepressant medication was greater than 1 for the co-morbidity cerebrovascular disease (model 1: adjusted OR = 1.78; CI: 1.16-2.74; model 2: adjusted OR = 1.76; CI: 1.12-2.76). Patients who had cancer were significantly less likely to be prescribed an antidepressant medication than those who had no cancer (model 1: adjusted OR $=0.65 ; \mathrm{CI}: 0.51-0.84 ;$ model 2: adjusted $\mathrm{OR}=0.75 ; \mathrm{CI}: 0.57-0.97)$. Finally model 2 also indicated $\mathrm{OR}<1$ for the co-morbidities heart failure and COPD.

Our data, however, suggest an increase in antidepressant medication over the time of the study period. While in 2004, a total of 579 patient were prescribed 360 antidepressant 
TABLE 3: Sample of patients with depression subdivided according to antidepressants.

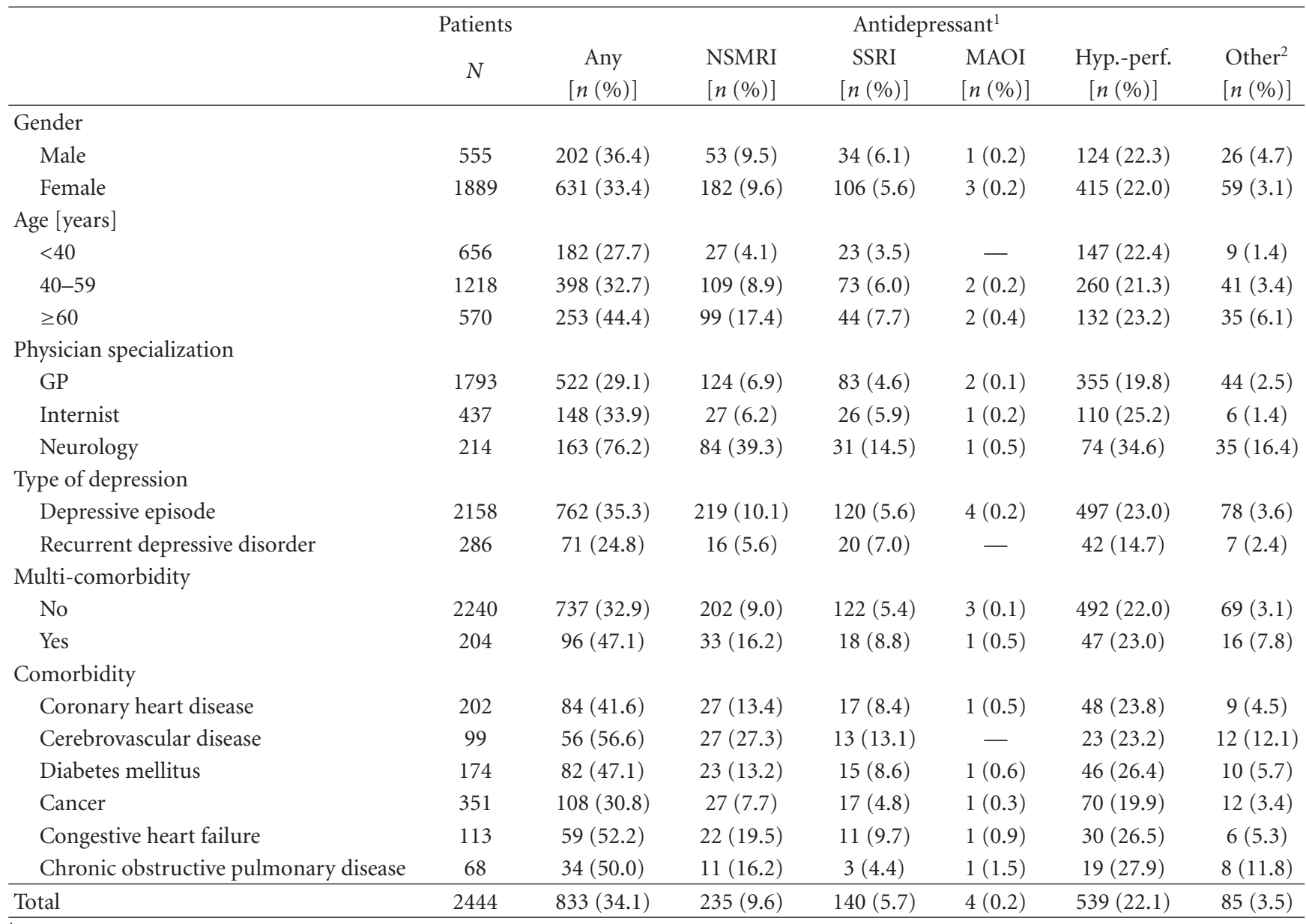

${ }^{1}$ Double entries possible, ${ }^{2}$ including bupropion, mirtazapine, and nefazodone.

MAOIs: non-selective monoamine oxidase A inhibitors.

NSMRI: non-selective monoamine reuptake inhibitors.

SSRIs: selective serotonin reuptake inhibitors.

Others: for example, bupropion, mirtazapine, and nefazodone.

drugs (mean 0.62), the amount of prescribed antidepressants almost doubled to a mean of 1.28 in 2008 (376 patients with 483 prescriptions).

\section{Discussion}

In this paper, we presented the results of a secondary data analysis of electronic health record data from the EvaMed-Network, a German network of physicians with a subspecialisation in anthroposophic medicine $[16,17,19]$ which aims at improving clinical practice by collecting prescription and ADR data.

In the current study, 2444 patients with a first diagnosis of depression fitted the inclusion criteria. A proportion of $8.3 \%$ of them were multi-morbid with more than two diagnoses. $33.9 \%$ of the patients received an antidepressant medication. The proportion of patients with medications is much less compared to the findings of, for example, 51.9\% by Robinson et al., $76.1 \%$, and accordingly $77.4 \%$ by Gill and colleagues in 2008 and 2010 respectively 2010 [2123]. This is even more of relevance as our patients received more complementary drug medication with phytotherapeutic preparations from Hypericum perforatum being the most prescribed drug over all. Within our study period, the number of psychiatric diseases and in particular depressive disorders in Germany significantly rose which is reflected in the data of prescription costs of antidepressants which according to health insurance data rose from 5 Mio. Euro in 2000 up to 14.5 Mio. Euro in 2009 [24]. Published data also suggest a higher proportion of female patients receiving such medication $[25,26]$. Both of these are strongly supported by our findings with three of four medicated patients being female and a doubling in the prescribed drugs per patient from 2004 to 2008 .

To improve the situation of people with depression in Germany, a first measure was the implementation of the German Disease Management Guideline (DMG-CPG) for depression $[6,8,9]$. The increased prescriptions of new antidepressive pharmacotherapies like SSRIs nowadays is 
TABLE 4: Likelihood of being prescribed any antidepressant medication by co-morbidity $(n=2444)$.

\begin{tabular}{|c|c|c|c|c|c|}
\hline \multirow{3}{*}{ Co-morbid condition } & \multicolumn{2}{|c|}{ Patients who were prescribed an antidepressant } & \multicolumn{3}{|c|}{ Likelihood of being prescribed antidepressant } \\
\hline & $\begin{array}{l}\text { Patients with } \\
\text { co-morbidity }\end{array}$ & $\begin{array}{l}\text { Patients without } \\
\text { co-morbidity }\end{array}$ & Unadjusted OR & $\begin{array}{c}\text { Model } 1 \\
\text { Adjusted OR }{ }^{1} \\
(95 \% \mathrm{CI})\end{array}$ & $\begin{array}{c}\text { Model } 2 \\
\text { Adjusted OR }{ }^{1} \\
(95 \% \mathrm{CI})\end{array}$ \\
\hline & $n / N(\%)$ & $n / N(\%)$ & & & \\
\hline Coronary heart disease & $84 / 202(41.6)$ & $749 / 2242(33.4)$ & $\begin{array}{c}1.419 \\
(1.058-1.903)^{*}\end{array}$ & $\begin{array}{c}1.028 \\
(0.753-1.404)\end{array}$ & $\begin{array}{c}1.191 \\
(0.864-1.643)\end{array}$ \\
\hline Cerebrovascular disease & $56 / 99(56.6)$ & $777 / 2345(33.1)$ & $\begin{array}{c}2.628 \\
(1.750-3.947)^{*}\end{array}$ & $\begin{array}{c}1.781 \\
(1.159-2.739)^{*}\end{array}$ & $\begin{array}{c}1.762 \\
(1.124-2.762)^{*}\end{array}$ \\
\hline Diabetes mellitus & $82 / 174(47.1)$ & $751 / 2270(33.1)$ & $\begin{array}{c}1.803 \\
(1.322-2.459)^{*}\end{array}$ & $\begin{array}{c}1.342 \\
(0.968-1.860)\end{array}$ & $\begin{array}{c}1.317 \\
(0.936-1.855)\end{array}$ \\
\hline Cancer & $108 / 351(30.8)$ & $725 / 2093(34.6)$ & $\begin{array}{c}0.829 \\
(0.657-1.070)\end{array}$ & $\begin{array}{c}0.652 \\
(0.505-0.842)^{*}\end{array}$ & $\begin{array}{c}0.745 \\
(0.572-0.969)^{*}\end{array}$ \\
\hline Congestive heart failure & $59 / 113(52.2)$ & $774 / 2331(33.2)$ & $\begin{array}{c}2.198 \\
(1.504-3.211)^{*}\end{array}$ & $\begin{array}{c}1.431 \\
(0.951-2.154)\end{array}$ & $\begin{array}{c}1.652 \\
(1.082-2.521)^{*}\end{array}$ \\
\hline $\begin{array}{l}\text { Chronic obstructive } \\
\text { Pulmonary disease }\end{array}$ & $34 / 68(50.0)$ & $799 / 2376(33.6)$ & $\begin{array}{c}1.974 \\
(1.218-3.199)^{*}\end{array}$ & $\begin{array}{c}1.612 \\
(0.986-2.638)\end{array}$ & $\begin{array}{c}1.950 \\
(1.188-3.200)^{*}\end{array}$ \\
\hline Any comorbidity & $267 / 708(37.7)$ & $566 / 1736(32.6)$ & $\begin{array}{c}1.252 \\
(1.043-1.502)^{*}\end{array}$ & $\begin{array}{c}0.878 \\
(0.709-1.086) \\
\end{array}$ & $\begin{array}{c}1.007 \\
(0.807-1.257) \\
\end{array}$ \\
\hline
\end{tabular}

${ }^{1}$ Odds ratio for patients who had a co-morbidity compared to patients who did not have co-morbidity.

Model 1: adjusted for patient age and gender.

Model 2: adjusted for patient age and gender, as well as for physician specialisation and type of depression.

critically discussed within the scientific community [26, 27]. One of their major concerns is the unjustified medication of mild and potentially self limiting depressive episodes with expensive medications with a high potential of adverse drug reactions.

Our study also gives data on the prescription of NSMRI $(28.2 \%)$ and SSRI $(16.8 \%)$ which is considerably below the German standard. One reason might be the compensation of such drug classes by the use of complementary drug therapies like Hypericum perforatum.

Several publication on prescriptions [24] state that citalopram, mirtazapin and amitriptylin are the most common and popular remedies for depression. We also found these three remedies to be the most often prescribed conventional drugs. However, we can not tell why the ranking in our study is the other way round (Amitriptylin, Mirtazapine followed by Citalopram). This may be due to the comparably longer time frame of our study or to the different sample of physicians. One explanation might also be that Amitriptylin is the "oldest" remedy and thus the most known.

In the treatment of depression, medication is only one issue; guidelines additionally focus on nonpharmacological treatments like psychotherapy, mind body techniques, or light therapy. These are also relevant therapeutic options which are very often underrepresented [23]. However, our data do not provide detailed information on such therapies.

With regards to comorbidities, studies have shown the prevalence of depression to be higher for persons with heart diseases, diabetes mellitus, stroke, COPD, and cancer [28]. This was also confirmed in the study of Gill et al. 2008, which found depression to be more likely among patients with a significant number of medical comorbidities [21]. In our study, $504(20.6 \%)$ had at least one comorbidity, while
204 patients (8.3\%) had two or more comorbidities. This is nearly comparable to the proportions provided in the study of Gill et al. from 2010, who found 20.7\% with one and $5.8 \%$ with two or more co-morbidities in their sample of 1513 patients [22]. They also found that after controlling for age and gender, patients with multiple comorbidities were less likely to be prescribed medication (adjusted odds ratio, 0.58; 95\% CI, 0.35-0.96). In our first multivariate model, which equates the approach of Gill et al., we were also able to show this effect but were not able to reach significance (adjusted odds ratio 0.88; 95\% CI, 0.71-1.09). A more detailed differentiation between the co-morbidities was not performed to guarantee the statistical model performance.

Although there is some comparability of our results with former studies, some discrepancies of our results with another German study of Jacobi et al. [29] have to be mentioned. Although the proportion for one comorbidity with $20.8 \%$ is quite similar, they found $39.9 \%$ of depressive patients with two or more comorbidities. This may be explained by the fact that all patients with one depressive episode form the basis of their study which is not comparable with our situation.

\section{Limitations}

The present study has several important limitations which should be taken into account when interpreting the results. Firstly, additional data on the depression diagnoses are lacking. We do not know to what extent the diagnoses were made, only clinically or with additional validated questionnaires, that is, as a functional evaluation with the WHO-5 or PHQ-D [30, 31]. We therefore are also not able to give detailed information on the severity of the depression. 
Secondly, although physician prescribing data were subjected to an internal review, coding inaccuracies cannot be ruled out entirely.

Thirdly, our data do not provide more detailed information on the type and dosage of phytotherapeutic Hypericum perforatum preparations. For the same methodological boundaries, our data also do not allow a calculation of daily drug doses, which limits the comparability of our data with other studies.

Fourthly, data on subsequent medication use in patients who switched physicians were unavailable.

Fifthly, our data from the group of 22 participating physicians are not representative for physicians in general practice in Germany nor may be seen as such for the smaller subgroup of anthroposophical physicians. The same problem arises for the patients the data are based on. Although an earlier paper gives an estimate for the prevalence of mood and affective disorders (F00-F39) of about $10 \%$ in our patients between 40 and 70 years in 2005 which is comparable to the numbers given, that is, in [7], it is less than the prevalence of $19.8 \%$ reported in [29]. Thus generalisations from this data are somehow limited.

Finally, although there were no major differences to the studies of Gill et al., the present study lacks a direct comparison group and the options to carry out detailed subgroup analyses. Further research on this subject would benefit from including a comparison group of conventional primary care physicians.

\section{Conclusion}

This study provides a comprehensive analysis of everyday practice for treatment of depression in primary care in physicians with subspecialisation in anthroposophic medicine $(\mathrm{AM})$. Although the administration of phytotherapeutic preparations from Hypericum perforatum was significantly higher, the prescribing frequency for conventional antidepressive drugs is partly comparable to those found in other studies.

\section{Authors' Contribution}

E. Jeschke participated in the design of the study and acquisition of data, performed the statistical analysis, and helped in drafting the paper. T. Ostermann drafted the manuscript and made substantial contributions to the interpretation of data and statistical analysis. H. C. Vollmar helped with the interpretation of the data and drafting and critical revision of the manuscript. M. Tabali helped in data acquisition and in drafting and critical revising the manuscript. $\mathrm{H}$. Matthes conceived the study and participated in its design and coordination. All authors read and approved the final manuscript.

\section{Acknowledgments}

The EvaMed Network was supported by grants from the Software AG Foundation, Wala Heilmittel GmbH, and
Weleda AG. The sponsors had no influence on the design, on implementation of the study, collection, management, or analysis of data or the preparation, review, or approval of the manuscript. The authors would also like to express their special gratitude to all participating physicians in the EvaMed Network.

\section{References}

[1] S. Moussavi, S. Chatterji, E. Verdes, A. Tandon, V. Patel, and B. Ustun, "Depression, chronic diseases, and decrements in health: results from the World Health Surveys," The Lancet, vol. 370, no. 9590, pp. 851-858, 2007.

[2] World Health Organisation, "Mental health, new understanding, new hope," World Health Report 2001, WHO, Geneva, Switzerland, 2001, http://www.who.int/whr/2001/en/whr01_ en.pdf.

[3] A. Bramesfeld, T. Grobe, and F. W. Schwartz, "Prevalence of depression diagnosis and prescription of antidepressants in East and West Germany: an analysis of health insurance data," Social Psychiatry and Psychiatric Epidemiology, vol. 45, no. 3, pp. 329-335, 2010.

[4] S. Ornstein, G. Stuart, and R. Jenkins, "Depression diagnoses and antidepressant use in primary care practices: a study from the practice partner research network (PPRNet), Journal of Family Practice, vol. 49, no. 1, pp. 68-72, 2000.

[5] A. Bramesfeld, T. G. Grobe, and F. W. Schwartz, "Who is diagnosed as suffering from depression in the German statutory health care system? An analysis of health insurance data," European Journal of Epidemiology, vol. 22, no. 6, pp. 397-403, 2007.

[6] "für die Leitliniengruppe Unipolare Depression," in S3Leitlinie/Nationale VersorgungsLeitlinie Unipolare DepressionLangfassung, DGPPN, BÄK, KBV et al., Eds., DGPPN, ÄZQ, AWMF, Berlin, Germany, 1st edition, 2009, http://www.dgppn .de/ http://www.versorgungsleitlinien.de/ http://awmf-leitlinien.de/.

[7] H. U. Wittchen, M. Höfler, and W. Meister, "Prevalence and recognition of depressive syndromes in german primary care settings: poorly recognized and treated?" International Clinical Psychopharmacology, vol. 16, no. 3, pp. 121-135, 2001.

[8] M. Härter, I. Bermejo, G. Ollenschläger et al., "Improving quality of care for depression: The German Action Programme for the implementation of evidence-based guidelines," International Journal for Quality in Health Care, vol. 18, no. 2, pp. 113-119, 2006.

[9] M. Härter, C. Klesse, I. Bermejo et al., "Evidence-based therapy of depression. S3 guidelines on unipolar depression," Nervenarzt, vol. 81, no. 9, pp. 1049-1068, 2010.

[10] E. Holsboer-Trachsler, J. Hättenschwiler, J. Beck et al., "Die somatische Behandlung der unipolaren depressiven Störungen," Schweiz Med Forum, vol. 10, pp. 802-809, 2010.

[11] A. V. Ravindran, R. W. Lam, M. J. Filteau et al., "Canadian Network for Mood and Anxiety Treatments (CANMAT) Clinical guidelines for the management of major depressive disorder in adults. V. Complementary and alternative medicine treatments," Journal of Affective Disorders, vol. 117, no. 1, pp. S54S64, 2009.

[12] S. Kasper, F. Caraci, B. Forti, F. Drago, and E. Aguglia, "Efficacy and tolerability of Hypericum extract for the treatment of mild to moderate depression," European Neuropsychopharmacology, vol. 20, no. 11, pp. 747-765, 2010. 
[13] K. Linde, M. M. Berner, and L. Kriston, "St John's wort for major depression," Cochrane Database of Systematic Reviews, no. 4, article CD000448, 2008.

[14] A. V. Dwyer, D. L. Whitten, and J. A. Hawrelak, "Herbal medicines, other than St. John's Wort, in the treatment of depression: a systematic review," Alternative Medicine Review, vol. 16, no. 1, pp. 40-49, 2011.

[15] J. R. T. Davidson, C. Crawford, J. A. Ives, and W. B. Jonas, "Homeopathic treatments in psychiatry: a systematic review of randomized placebo-controlled studies," Journal of Clinical Psychiatry, vol. 72, no. 6, pp. 795-805, 2011.

[16] E. Jeschke, T. Ostermann, M. Tabali et al., "Diagnostic profiles and prescribing patterns in everyday anthroposophic medical practice- a prospective multi-centre study," Forschende Komplementarmedizin, vol. 16, no. 5, pp. 325-333, 2009.

[17] M. Tabali, E. Jeschke, C. M. Witt, T. Ostermann, and H. Matthes, "Adverse drug reactions for CAM and Conventional drugs detected in a network of Physicians Certified to prescribe CAM drugs," Journal of Managed Care Pharmacy, vol. 18, no. 6, pp. 427-438, 2012.

[18] Arbeitsgruppe Erhebung und Nutzung von Sekundärdaten der Deutschen Gesellschaft für Sozialmedizin und Prävention, Arbeitsgruppe Epidemiologische Methoden der Deutschen Gesellschaft für Epidemiologie, Deutschen Gesellschaft für Medizinische Informatik, Biometrie und Epidemiologie, and Deutschen Gesellschaft für Sozialmedizin und Prävention, "Good practice of secondary data analysis, first revision," Gesundheitswesen, vol. 701, pp. 54-60, 2008.

[19] E. Jeschke, F. Schad, J. Pissarek, B. Matthes, U. Albrecht, and H. Matthes, "QuaDoSta—ein frei konfigurierbares System zur Unterstützung multizentrischer Datenerhebungen in medizinischer Versorgung und Forschung," GMS Medizinische Informatik, Biometrie Und Epidemiologie, vol. 3, no. 10, 2007.

[20] Kassenärztliche Bundesvereinigung (KBV), "Grunddaten zur Vertragsärztlichen Versorgung in Deutschland 2011," http://www.kbv.de/publikationen/125.html.

[21] J. M. Gill, X. C. Ying, and M. I. Lieberman, "Management of depression in ambulatory care for patients with medical comorbidities: a study from a national electronic health record (EHR) network," International Journal of Psychiatry in Medicine, vol. 38, no. 2, pp. 203-215, 2008.

[22] J. M. Gill, M. S. Klinkman, and Y. X. Chen, "Antidepressant medication use for primary care patients with and without medical comorbidities: a national Electronic Health Record (EHR) network study," Journal of the American Board of Family Medicine, vol. 23, no. 4, pp. 499-508, 2010.

[23] W. D. Robinson, J. A. Geske, L. A. Prest, and R. Barnacle, "Depression treatment in primary care," Journal of the American Board of Family Practice, vol. 18, no. 2, pp. 79-86, 2005.

[24] M. Sieberer, "Auswertungsergebnisse der BARMER GEK Arzneimitteldaten aus den Jahren 2008 und 2009," in BARMER GEK Arzneimittel-Report 2010, G. Glaeske and C. Schicktanz, Eds., vol. 2, pp. 137-149, Schriftenreihe zur Gesundheitsanalyse, 2010.

[25] T. Grobe and H. Dörning, Gesundheits report 2010 - Veröffentlichungen zum Betrieblichen Gesundheitsmanagement der TK, vol. 24, Techniker Krankenkasse, Hamburg, Germany, http://www.tk-online.de/.

[26] J. Moncrieff and D. Cohen, "Do antidepressants cure or create abnormal brain states?" PLoS Medicine, vol. 3, no. 7, article e240, 2006.

[27] I. Kirsch, B. J. Deacon, T. B. Huedo-Medina, A. Scoboria, T. J. Moore, and B. T. Johnson, "Initial severity and antidepressant benefits: a meta-analysis of data submitted to the food and drug administration," PLoS Medicine, vol. 5, no. 2, article e45, 2008.

[28] W. Katon and M. D. Sullivan, "Depression and chronic medical illness," Journal of Clinical Psychiatry, vol. 51, 1, pp. 3-11, 1990.

[29] F. Jacobi, H. U. Wittchen, C. Hölting et al., "Prevalence, comorbidity and correlates of mental disorders in the general population: results from the German Health Interview and Examination Survey (GHS)," Psychological Medicine, vol. 34, no. 4, pp. 597-611, 2004.

[30] World Health Organization (WHO), Wellbeing Measures in Primary Health Care: The DepCare Project, WHO, Copenhagen, Denmark, 1998.

[31] R. L. Spitzer, K. Kroenke, and J. B. W. Williams, "Validation and utility of a self-report version of PRIME-MD: the PHQ Primary Care Study," Journal of the American Medical Association, vol. 282, no. 18, pp. 1737-1744, 1999. 


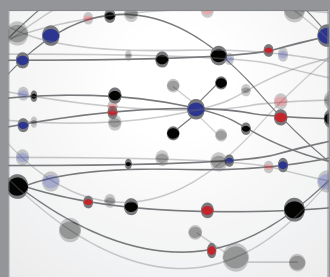

The Scientific World Journal
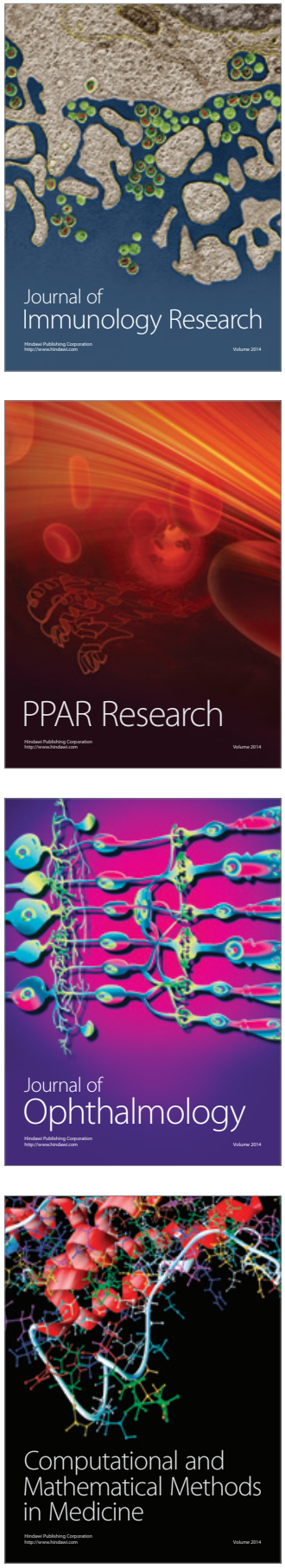

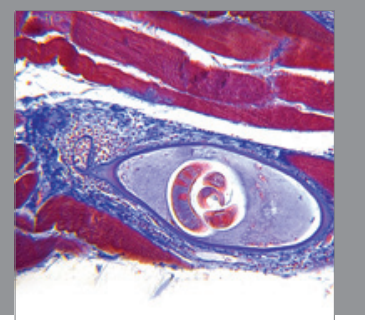

Gastroenterology

Research and Practice
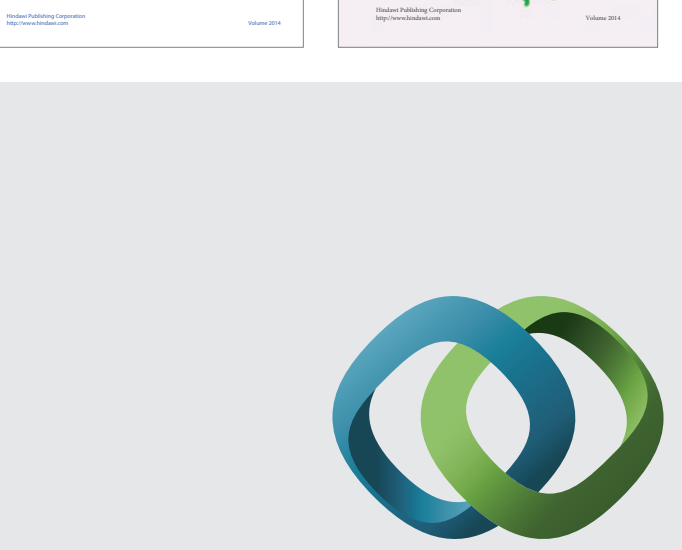

\section{Hindawi}

Submit your manuscripts at

http://www.hindawi.com
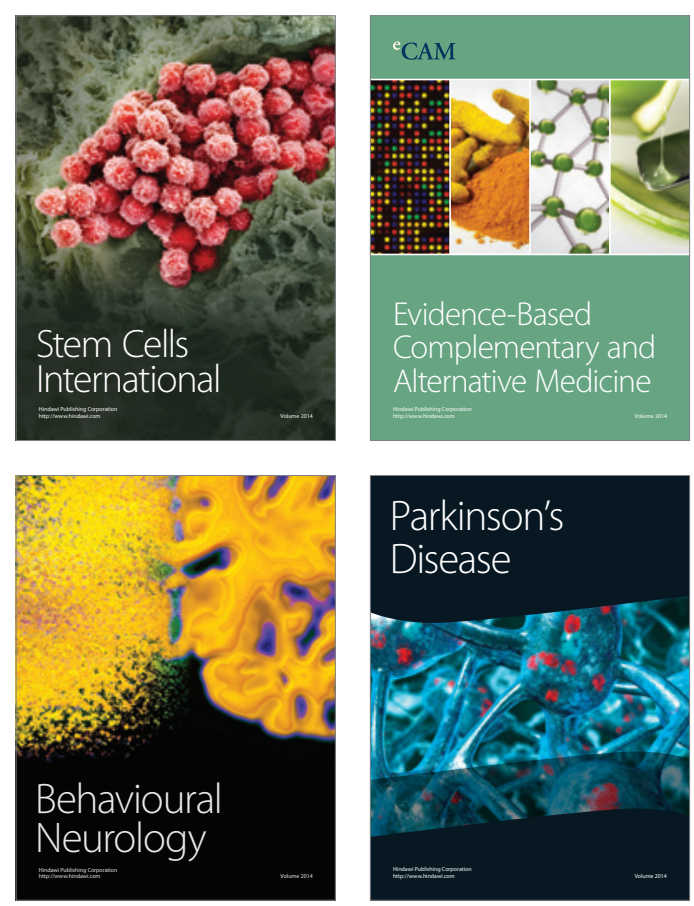

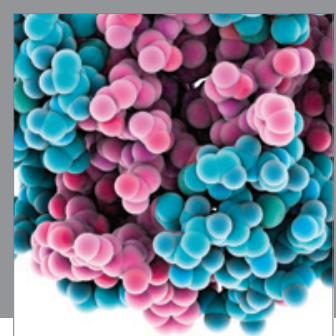

Journal of
Diabetes Research

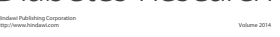

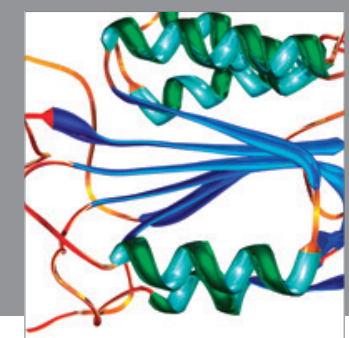

Disease Markers
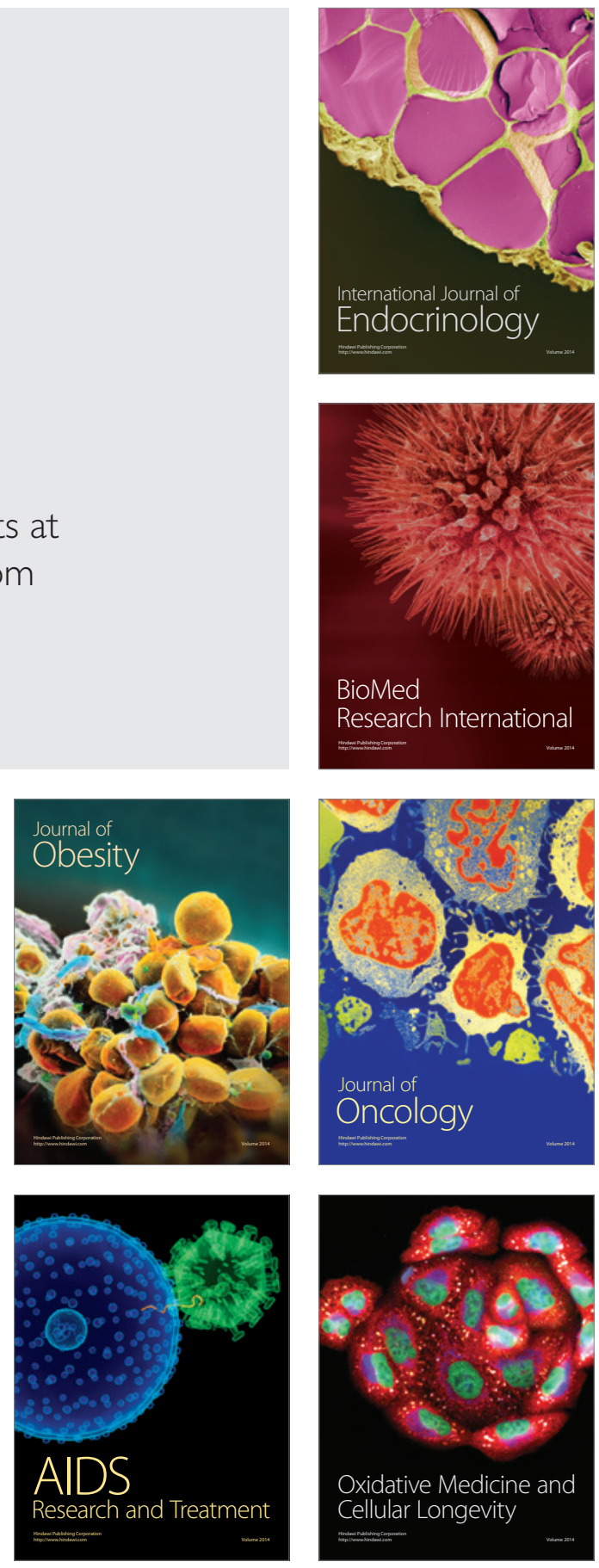